\title{
Intercomparison of total column ozone data from the Pandora spectrophotometer with Dobson, Brewer, and OMI measurements over Seoul, Korea
}

\author{
Jiyoung Kim ${ }^{1}$, Jhoon Kim ${ }^{1}$, Hi-Ku Cho ${ }^{1}$, Jay Herman ${ }^{2,3}$, Sang Seo Park ${ }^{1,4}$, Hyun Kwang Lim ${ }^{1}$, Jae-Hwan Kim ${ }^{5}$, \\ Koji Miyagawa ${ }^{6,7}$, and Yun Gon Lee ${ }^{8}$ \\ ${ }^{1}$ Department of Atmospheric Sciences, Yonsei University, Seoul, South Korea \\ ${ }^{2}$ Joint Center for Earth Systems Technology, University of Maryland, Baltimore, MD 20771, USA \\ ${ }^{3}$ NASA Goddard Space Flight Center, Greenbelt, MD 20771, USA \\ ${ }^{4}$ School of Earth and Environmental Sciences, Seoul National University, Seoul, South Korea \\ ${ }^{5}$ Department of Atmospheric Science, Pusan National University, Busan, South Korea \\ ${ }^{6}$ Science \& Technology Corp, Hampton, VA 23666-1393, USA \\ ${ }^{7}$ NOAA/ESRL, Global Monitoring Division, Boulder, CO 80305, USA \\ ${ }^{8}$ Department of Atmospheric Sciences, Chungnam National University, Daejeon, South Korea
}

Correspondence to: Jhoon Kim (jkim2@yonsei.ac.kr)

Received: 26 April 2016 - Discussion started: 14 July 2016

Revised: 9 May 2017 - Accepted: 15 August 2017 - Published: 6 October 2017

\begin{abstract}
Daily total column ozone (TCO) measured using the Pandora spectrophotometer (no. 19) was compared with data from the Dobson (no. 124) and Brewer (no. 148) spectrophotometers, as well as from the Ozone Monitoring Instrument (OMI) (with two different algorithms, Total Ozone Mapping Spectrometer (TOMS) TOMS and differential optical absorption spectroscopy (DOAS) methods), over the 2-year period between March 2012 and March 2014 at Yonsei University, Seoul, Korea. Based on the linearregression method, the TCO from Pandora is closely correlated with those from other instruments with regression coefficients (slopes) of 0.95 (Dobson), 1.00 (Brewer), 0.98 (OMITOMS), and 0.97 (OMI-DOAS), and determination coefficients (R2) of 0.95 (Dobson), 0.97 (Brewer), 0.96 (OMITOMS), and 0.95 (OMI-DOAS). The daily averaged TCO from Pandora has within $3 \%$ differences compared to TCO values from other instruments. For the Dobson measurements in particular, the difference caused by the inconsistency in observation times when compared with the Pandora measurements was up to $12.5 \%$ because of diurnal variations in the TCO values. However, the comparison with Brewer after matching the observation time shows agreement with large $R^{2}$ and small biases. The TCO ratio between Brewer and Pandora shows the $0.98 \pm 0.03$, and the distributions for
\end{abstract}

relative differences between two instruments are 89.2 and $57.1 \%$ of the total data within the error ranges of 3 and $5 \%$, respectively. The TCO ratio between Brewer and Pandora also is partially dependent on solar zenith angle. The error dependence by the observation geometry is essential to the further analysis focusing on the sensitivity of aerosol and the stray-light effect in the instruments.

\section{Introduction}

Approximately $90 \%$ of total column ozone (TCO) is found in the stratosphere, and its density peak occurs at altitudes between 20 and $30 \mathrm{~km}$ (Liou, 2002; Schott, 2007). This layer is essential to the biosphere as it absorbs harmful solar ultraviolet (UV) radiation. In addition, UV absorption by ozone influences global radiative forcing and climate change over long timescales (e.g., Cho et al., 2003; Martens, 1998; WMO, 2014). Since the depletion of ozone layer was first reported in the 1980s (Farman et al., 1985; Chubachi, 1985), extensive studies have been conducted on its long-term trends (e.g., Stolarski et al., 1991; Harris et al., 1997; Reinsel et al., 1981; Reinsel and Tiao, 1987; Ziemke et al., 2005; Fio- 
letov et al., 2002) with consideration of solar activity (e.g., Angell, 1989; Zerefos et al., 2001; Harris et al., 2003), natural oscillations (Creilsen et al., 2005; Appenzeller et al., 2000), detailed chemical mechanism (e.g., Solomon, 1999), slowdown of ozone depletion in upper stratosphere (e.g., Newchurch et al., 2003; Stolarski and Frith, 2006), detection of ozone hole recovery (e.g., Weatherhead et al., 2000; Reinsel et al., 2005), and recent assessment of physical/chemical cause of ozone layer healing based on the observation studies (Solomon et al., 2016). The concentration of anthropogenic ozone-depleting substances (ODSs) has decreased; consequently, global ozone amounts should return to 1980 levels during the 21st century (e.g., WMO, 2014).

Over several decades, ground-based instruments such as Dobson or Brewer spectrophotometers have been used widely to obtain stable and highly accurate long-term measurements of global ozone amounts. The Dobson spectrophotometer was developed in 1928 by G. M. B. Dobson to measure TCO levels under clear-sky conditions (Dobson, 1968). TCO values are retrieved by measuring direct or scattered intensity ratios at two wavelength pairs that have different absorption features in the UV (A pair: 305.5 and $325.4 \mathrm{~nm}$; D pair: 317.6 and $339.8 \mathrm{~nm}$; recommended by the World Meteorological Organization (WMO); Komhyr et al., 1980; Leonard, 1989). Since the Brewer spectrophotometer was developed in the early 1980s, its automated operation has provided high temporal resolution observation together with Dobson spectrophotometers (e.g., Brewer, 1973; Kerr et al., 1985; Kerr, 2010). The measurement principle is similar to that of the Dobson instrument, but with improved technologies and automated operation; the Brewer spectrophotometer retrieves data on total UV (TUV), erythemal UV (EUV), TCO, and aerosol optical depth (AOD) in UV, as well as trace gases such as $\mathrm{NO}_{2}$ and $\mathrm{SO}_{2}$, by measuring solar irradiance and zenith sky radiance spectra. In addition, many instruments to measure TCO have been installed, and their global network has been established extensively to monitor TCO amounts and to retrieve its vertical profile using Umkehr measurements since the 1980s (e.g., Goetz et al., 1934; Duetsch, 1959; Petropavlovskikh et al., 2005). For the satellite-based observations, long-term, global datasets have been provided with high accuracy by the Total Ozone Mapping Spectrometer (TOMS) since 1979 (Bhartia and Wellemeyer, 2002), succeeding the Solar Backscattered Ultraviolet (SBUV) and SBUV2, Global Ozone Monitoring Experiment (GOME), Scanning Imaging Absorption Spectrometer for Atmospheric chartography (SCIAMACHY), and Ozone Monitoring Instrument (OMI) (Levelt et al., 2006). These data have been validated globally over long periods and have been widely used in numerous studies (e.g., Balis et al., 2007; McPeters et al., 2008; WMO, 2014).

Recently, the Pandora spectrophotometer (PAN hereafter) was developed at NASA's Goddard Space Flight Center in 2006 to measure the concentrations of trace gases including ozone (Herman et al., 2009; Cede, 2013). The Pandora is an array detector instrument for simultaneous and continuous observation with wide spectral ranges (Herman et al., 2009). With the advantage of continuous spectral radiance observation with high signal-to-noise ratio, the Pandora spectrometer system is a recently developed ground-based monitoring instrument for trace gases, including total ozone and pollutants, to help understand the process of urban air quality and validation of satellite measurements (Tzortzion et al., 2012). In Seoul and Busan, the Pandora spectrometer was first installed in 2012 for the preparation of the Distributed Regional Aerosol Gridded Observation Networks (DRAGON)NE Asia campaign and validation for Geostationary Environment Monitoring Spectrometer (GEMS) satellite missions, which is the next geostationary satellite mission of South Korea to measure ozone and its precursors. The Dobson and Brewer spectrophotometers have been operated since 1984 and 1997, respectively, to monitor the TCO.

In this study, the Pandora in Seoul is compared with two independent ground-based and two satellite datasets over a 2year period from 2012 to 2014. Furthermore, the difference between Pandora and other measurements, and the causes of these differences, are discussed. This paper is organized as follows. Section 2 describes the ground-based and satellite datasets used in this study. Section 3 describes the methodology and results of the comparison together with our analysis and discussion. In addition, high-resolution diurnal variations in the Pandora TCO data are compared with Dobson and Brewer measurements. Finally, our conclusions are summarized in Sect. 4.

\section{Instruments and data}

\subsection{Dobson spectrophotometer (Beck no. 124)}

The Dobson spectrophotometer (Beck no. 124) is located on the rooftop of the Science Hall of Yonsei University and has been in operation since 1984, with its operation automated first in 2005 for total ozone measurements (Cho, 1996; Cho et al., 1989, 2003; Kim et al., 2005). This instrument is a standard instrument for TCO over Korea as a WMO/GAW site (station no. 252). The instrument retrieves TCO from the observed UV radiance in direct-sun (DS) and zenith-sky (ZS) modes three times a day with an air mass factor (AMF) of 2.5. A DS TCO value measured at noon under clear skies is generally selected as a representative value; however, a value close to noon or the ZS measurement can be used instead when DS data from noon are unavailable. After the automation of the Dobson instrument (in particular, Q levers, attenuator, $\mathrm{R}$ dial, observation, and data processing with test) in 2006, accuracy was improved such that the proportion of data points within a $\pm 3 \%$ error range increased from 92 to $98 \%$ (Kim et al., 2007; Miyagawa et al., 2005). This Dobson was calibrated regularly against the standard instrument, with the most recent one done by NOAA in August-October 
2014. The calibration history of this instrument was summarized by Kim et al. (2007) and Hong et al. (2014), and weekly regular standard lamp and monthly mercury lamp tests have been performed to check radiometric and spectral accuracy, respectively. Because of limitation in observation two to three times per day by the Dobson spectrophotometer (DBS hereafter), the TCO from the DBS has not been available to the diurnal variation of ozone amount. However the DBS has provided a high-quality, reliable dataset that can be used to monitor the variations and trends in ozone levels over the Korean Peninsula. The TCO dataset from the DBS was utilized to assess the long-term trends and their relationship with the secondary ozone peak (Park et al., 2012; Kim et al., 2005, 2014).

\subsection{Brewer spectrophotometer (SCI-TEC no. 148)}

The TCO accuracy of well-calibrated Brewer measurements is estimated to be about $1 \%$ for direct-sun observations. Nearly 200 Brewer instruments are now operating in about 40 countries (Kerr, 2010). A MKIV version has been in operation at Yonsei University, Seoul, Korea, since 1997 (Kim et al., 2011) and has been regularly calibrated by the official technical support, six times in 7 years from 2004 to 2013 (March 2004, February 2006, October 2007, October 2009, November 2011, August 2013), and the standard lamp tests for wavelength and radiance calibrations have been carried out (Kim et al., 2014). Therefore, the TCO data from the Brewer spectrophotometer were well calibrated during the comparison period. The Brewer spectrophotometer (BRE hereafter) observes the UV wavelength region from 290 to $363 \mathrm{~nm}$ with a spectral resolution of $0.5 \mathrm{~nm}$ on a horizontal surface (cf. Sabburg et al., 2002). It also measures normal direct UV radiation, which can be used to retrieve TCO using five wavelengths in the UV region $(306.3,310.1,313.5$, 316.7, and $320.0 \mathrm{~nm}$; e.g., Kerr et al., 1985; Kerr, 2002; Kim et al., 2011). The data from the BRE have been used in several previous studies for annual EUV and TUV (Kim et al., 2011) and for AOD at $320 \mathrm{~nm}$ (Kim et al., 2014). Normally, the BRE at Seoul observes TCO with intervals of tens of minutes, with two different observation modes, DS and ZS measurements, similar to the DBS. However, the ZS-measured TCO is based on the estimation value by the statistical regression approaches by comparing simultaneous observed TCO from DS and ZS under clear-sky conditions. For this reason, DS-measured TCO is more suitable for the comparison test than those from ZS (e.g., Hong et al., 2014; De Backer and De Muer, 1991; Balis et al., 2007). Although the ZS data are partially used from DBS due to its small observation number, the DS data are fully used from BRE for this analysis.

\subsection{Ozone Monitoring Instrument}

The OMI on board the Aura satellite has been dedicated to monitoring ozone and trace gases for air quality and climate studies since 2004. This instrument detects the molecular absorption of backscattered solar light in the visible and UV wavelengths $(270-500 \mathrm{~nm})$ with a spatial resolution of $13 \times 24 \mathrm{~km}^{2}$ at nadir (Buchard et al., 2008; Levelt et al., 2006). The Aura is in a sun-synchronous orbit with $98^{\circ}$ inclination angle. The Equator-crossing time for ascending node is approximately 13:30 local time; thus the OMI observation at Seoul is mostly from the afternoon, occurring once or twice a day. The total ozone product from the OMI is calculated using two different algorithms: the TOMS algorithm (e.g., Bhartia and Wellemeyer, 2002; Balis et al., 2007; MePeters et al., 2008) and the differential optical absorption spectroscopy (DOAS) algorithm (Veefkind et al., 2006), which show fairly good agreement, with correlation coefficients ranging from 0.89 to 0.99 (Antón et al., 2009; Kroon et al., 2008; McPeters et al., 2008). The TOMS algorithm (OMT hereafter) uses two wavelengths: a weak absorption wavelength $(331.2 \mathrm{~nm})$ and a strong absorption wavelength $(317.5 \mathrm{~nm})$ to retrieve TCO. The derivation applies tables calculated by the TOMS forward model (TOMRAD), which is based on successive iterations of the characteristic equation in the theory of radiative transfer developed by Dave (1964) (Bhartia and Wellemeyer, 2002; McPeters et al., 2008). The DOAS algorithm (OMD hereafter) derives TCO using the DOAS method, and the derivation follows three steps. First, spectral fitting is performed (Platt and Stutz, 2008; Veefkind et al., 2006) to obtain the slant column density (SCD); second, the SCD is converted to the vertical column density (VCD) using the AMF. The final step in the derivation procedure is a correction for the cloud effect (e.g., Hong et al., 2014; McPeters et al., 2008). For the level 3 daily product used in this study, this step consists of gridding and averaging the level $2 \mathrm{TCO}$ orbital swath data onto the $0.25^{\circ} \times 0.25^{\circ}$ global grids after a quality check.

\subsection{Pandora spectrophotometer (no. 19)}

A Pandora spectrophotometer (no. 19) is a passive system that measures direct sunlight from 280 to $525 \mathrm{~nm}$ using a UV-sensitive charge-coupled device detector of $2048 \times 16$ pixels with a spectral resolution of $0.6 \mathrm{~nm}$ and two UV band-pass filters of BP300 (280-320 nm) and U340 (280$380 \mathrm{~nm}$ ). The temporal resolution of the PAN is about $2 \mathrm{~min}$ (Tzortziou et al., 2012; Yun et al., 2013). PAN was installed at the same location as the DBS and BRE at Yonsei University as part of the DRAGON-NE Asia campaign in South Korea in 2012 (http://aeronet.gsfc.nasa.gov/new_web/ DRAGON-Asia_2012_Japan_South_Korea.html) and has been operational since March 2012 to monitor $\mathrm{NO}_{2}$ and $\mathrm{O}_{3}$ for total column amount. The PAN at Seoul was calibrated prior to the ground-based campaigns of DRAGON- 
Table 1. TCO retrieval methods with respect to instruments.

\begin{tabular}{|c|c|c|c|c|c|}
\hline Instrument & Retrieval method & Cross section database & $T_{\mathrm{O}_{3}}$ & Data frequency & Key reference \\
\hline Pandora & $\begin{array}{l}\text { Spectral fitting } \\
(310-330 \mathrm{~nm})\end{array}$ & $\begin{array}{l}\text { Brion et al. (1993, } \\
\text { 1998) and Malicet et al. } \\
(1995)\end{array}$ & $225 \mathrm{~K}$ & $2 \mathrm{~min}$ & Herman et al. (2015) \\
\hline Dobson & $\begin{array}{l}4 \text { wavelengths } \\
(305.5, \quad 317.5,325.0 \text {, } \\
\text { and } 339.9 \mathrm{~nm})\end{array}$ & Bass and Paur (1985) & $226.8 \mathrm{~K}$ & 3 times per day & Evans and Komhyr (2008) \\
\hline Brewer & $\begin{array}{l}5 \text { wavelengths } \\
(306.3, \quad 310.1, \quad 313.5, \\
316.7,320.0 \mathrm{~nm})\end{array}$ & Daumont et al. (1992) & $228 \mathrm{~K}$ & Tens of minutes & Kerr (2002) \\
\hline OMI-TOMS & $\begin{array}{l}2 \text { wavelengths } \\
(317.5 \text { and } 331.2 \mathrm{~nm})\end{array}$ & Bass and Paur (1985) & Varied & 1 time per day & Bhartia and Wellemeyer (2002) \\
\hline OMI-DOAS & $\begin{array}{l}\text { DOAS } \\
(331.1-336.6 \mathrm{~nm})\end{array}$ & Bass and Paur (1985) & Varied & 1 time per day & Veefkind et al. (2006) \\
\hline
\end{tabular}

NE in 2012 and the Korea-United States Air Quality Study (KORUS-AQ) campaign in 2016, and during upgrades in between it thus used the same calibration for the 2-year period of current analysis. The spectral stray-light effect is corrected by the offset subtraction, by using the signal change at the unilluminated pixels at shorter wavelength. In addition, the stray-light effect is also smoothed out during the polynomial subtraction to correct spectral aerosol signals. PAN uses an algorithm of spectral fitting over the entire $310-330 \mathrm{~nm}$ wavelength range to retrieve ozone amounts, which is different from DBS and BRE (Herman et al., 2015).

\subsection{Data selection for comparison}

An overview of the data selection for comparisons is listed in Table 1 with key parameters for the TCO retrieval algorithm. From Table 1, the cross section database and effective temperature for ozone absorption are slightly different among these ozone instruments. The cross section for ozone absorption is used as in Bass and Paur (1985) for OMI and DBS, Daumont et al. (1992) for BRE, and Brion et al. (1993, 1998) and Malicet et al. (1995) (BDM) for PAN. In OMI, BRE, and DBS, the assumed effective temperature for ozone absorption is also slightly different. Although the cross section database and retrieval methods have discrepancies among the different instruments, this study used the operational TCO value as a reference. Because of limitation in observation frequency for the DBS and OMI, intercomparison analysis is based on the daily averaged data. However, as the BRE and PAN observe TCO simultaneously in several minute intervals, these two instruments can analyze the diurnal variation in addition. The daily TCO datasets were calculated using the following methods. For PAN and BRE, only the data obtained from the DS measurements were averaged to obtain a single representative daily value. For the PAN data in particular, to avoid errors associated with cloud contamination and stray-light effects, the data were selected using the following criteria: root mean square of weighted spectral fitting residuals $<0.05$, solar zenith angle (SZA) $<75^{\circ}$, and uncertainty of TCO due to spectral fitting $<2 \mathrm{DU}$ as suggested in previous studies (Herman et al., 2015; Reed et al., 2015; Tzortziou et al., 2012). For the DBS, daily values measured in DS mode under a clear sky were averaged for the comparison. Finally, for the OMI instruments, the daily level 3 gridded data, the OMTO3e from the TOMStype algorithm, and the OMDOAO3e from the DOAS technique, together with site information from Yonsei University, were spatially interpolated. Although PAN and BRE data can be respectively calculated to the representative daily data based on the observation time of OMI and DBS, daily values are obtained using the above methods. For the instantaneous diurnal-cycle analysis, instantaneous data between BRE and PAN are compared and analyzed with the temporal colocation criteria within $\pm 5 \mathrm{~min}$. The real-time PAN data are averaged over all data within 5 min of the BRE observation time.

\section{Results}

\subsection{TCO measured by the Pandora, Dobson, Brewer, and $\mathrm{OMI}$ instruments}

The time series of measurements from the four instruments are shown in Fig. 1 for comparison, which range within 230$500 \mathrm{DU}$ and show similar seasonal variations. These seasonal variations are caused by changes to the Brewer-Dobson circulation in the Northern Hemisphere (Brewer, 1949; Wang et al., 2015; Weber et al., 2003). In addition, Fig. 2 shows similar annual cycles with amplitude of about $0.15 \%$ of the average values for the four different instruments. Maximum and minimum values of 2-year averaged monthly TCO and annual ranges are also shown in this figure. All statistics were derived by the data illustrated in Fig. 1 under the condition that the valid number of daily observations was greater than 10 days per month. In this figure, the largest maximum 
(a)

(b)
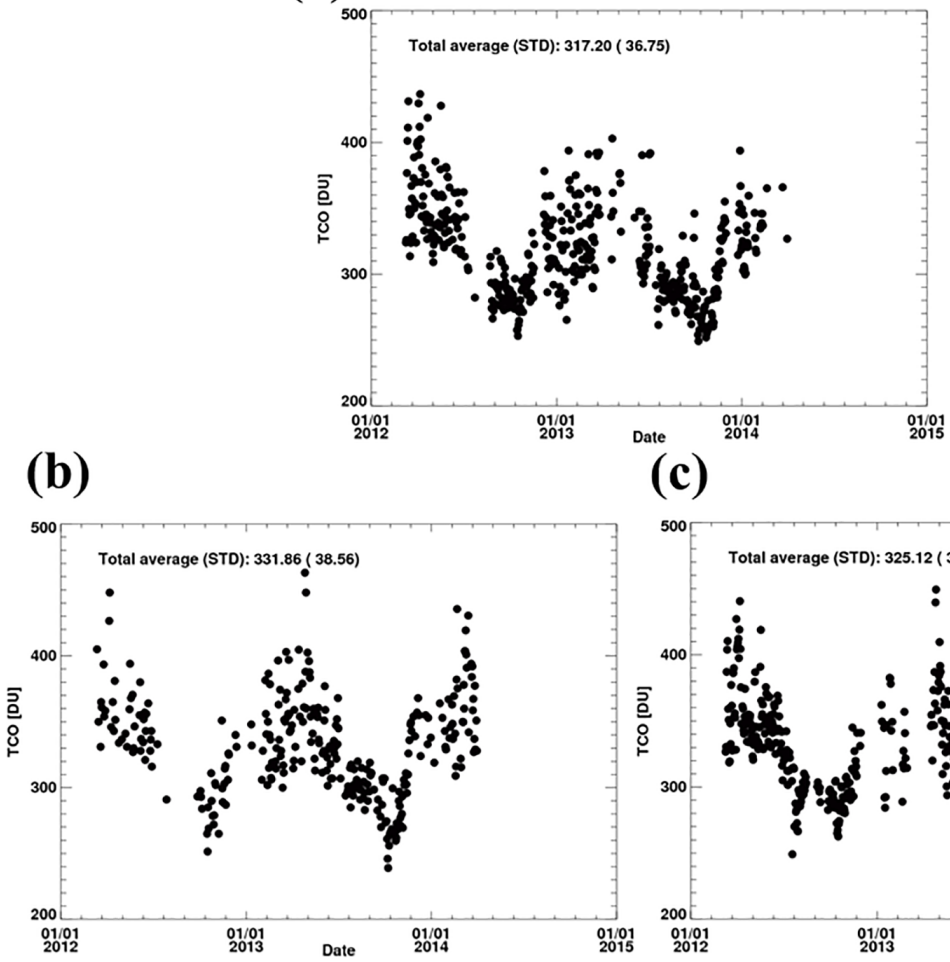

(c)

(d)
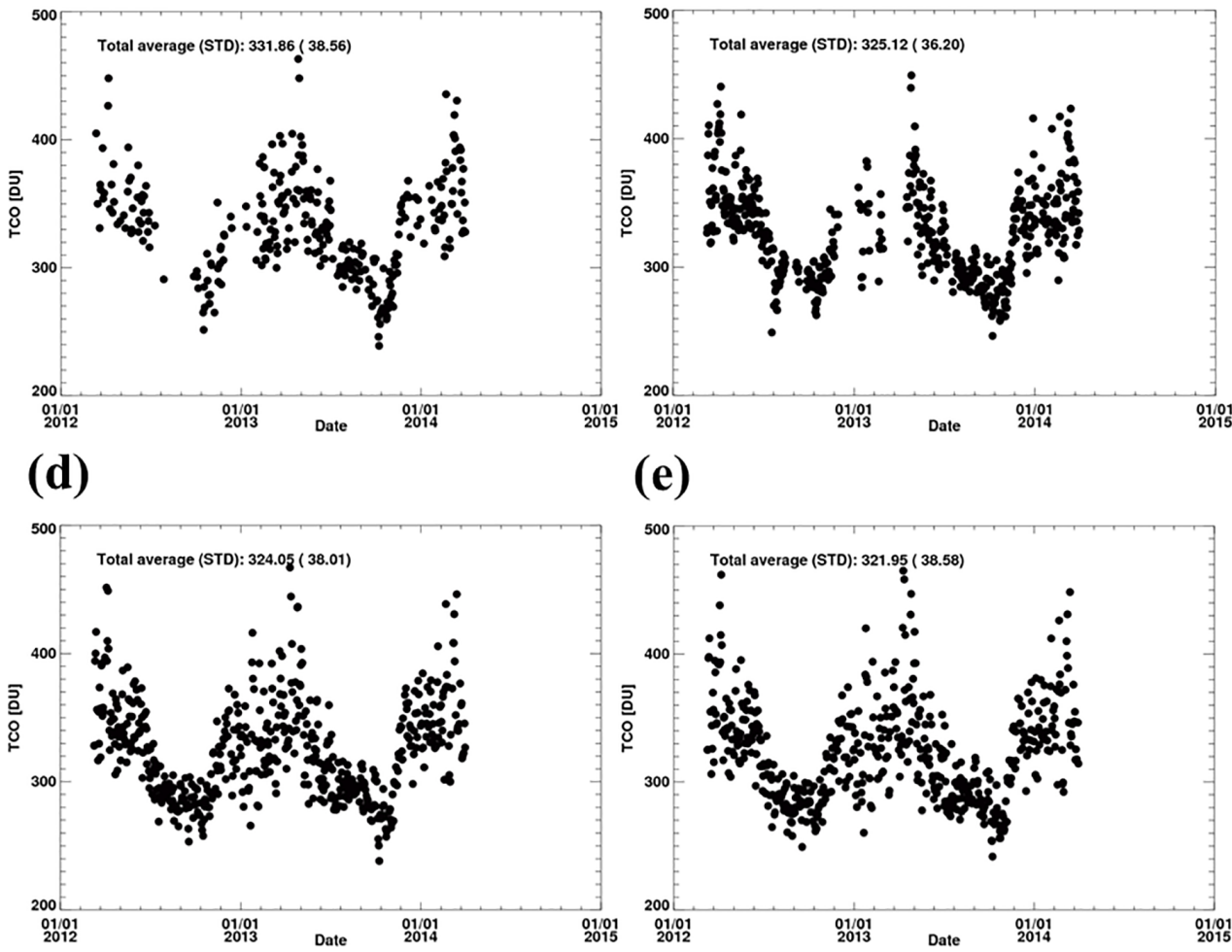

(e)

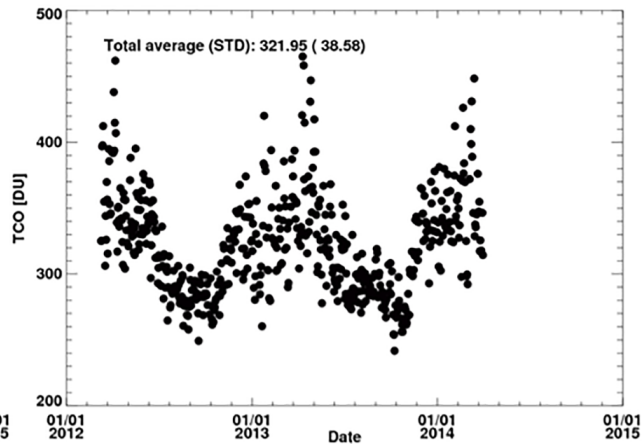

Figure 1. Daily TCO values for the 2 years from March 2012 to March 2014 from the following instruments: (a) Pandora, (b) Dobson, (c) Brewer, (d) OMI-TOMS, and (e) OMI-DOAS.

monthly mean TCO values are from the DBS (i.e., $371.5 \mathrm{DU}$ in April), and the smallest minimum monthly mean TCO values are from the PAN (i.e., 268.9 DU in October). The largest annual range is found in the DBS (101.7 DU), whereas the smallest range is in the BRE (81.3 DU). Larger values of annual range appear for the instruments with few observation numbers, DBS and OMI. The data from DBS and OMI are instantaneous values at a specific time; thus, these may reflect the sudden change of total ozone amounts due to stratosphere-troposphere exchange of ozone in winter and spring (e.g., Hwang et al., 2007; Park et al., 2012). The maximum monthly mean TCO value of the PAN shows the smallest relative difference of $1.54 \%$ with that of the BRE. The minimum monthly mean TCO value of the PAN shows the smallest relative difference with that of the DBS of $0.37 \%$. The OMD also showed the smallest difference in minimum value from that of the PAN of $0.37 \%$.

Table 2 shows the average, standard deviation, and maximum and minimum values of the daily TCO data measured by the four instruments, together with the relative differences among the PAN, DBS, BRE, and OMI data. The largest maximum and smallest minimum TCO values were 467.1 DU on 10 April 2013 and 238.3 DU on 8 October 2013, respectively, measured by OMT. For the 2-year average TCO value, the DBS was the largest at $331.9 \mathrm{DU}$ and with a standard deviation of 38.6. In contrast, the PAN showed the smallest 2- 
Table 2. Summary of intercomparison statistics for the 2 years from March 2012 to March 2014.

\begin{tabular}{|c|c|c|c|c|c|}
\hline & $\begin{array}{r}\text { Pandora } \\
(\text { PAN) }\end{array}$ & $\begin{array}{r}\text { Dobson } \\
\text { (DBS) }\end{array}$ & $\begin{array}{r}\text { Brewer } \\
(\mathrm{BRE})\end{array}$ & $\begin{array}{r}\text { OMI-TOMS } \\
(\mathrm{OMT})\end{array}$ & $\begin{array}{r}\text { OMI-DOAS } \\
(\mathrm{OMD})\end{array}$ \\
\hline Average [DU] & 317.2 & 331.9 & 325.1 & 324.1 & 322.0 \\
\hline Max (date) & 436.7 (6 Apr 2012) & 463.0 (26 Apr 2013) & 449.3 (26 Apr 2013) & 467.1 (10 Apr 2013) & 465.1 (10 Apr 2013) \\
\hline Min (date) & 249.2 (7 Oct 2013) & 239.0 (7 Oct 2013) & 246.5 (7 Oct 2013) & 238.3 (8 Oct 2013) & 241.8 (8 Oct 2013) \\
\hline
\end{tabular}

\begin{tabular}{rrrr}
\hline \multicolumn{4}{c}{ Mean relative difference [\%] } \\
\hline DBS-PAN & BRE-PAN & OMT-PAN & OMD-PAN \\
\hline 3.64 & 2.31 & 2.55 & 2.01 \\
\hline
\end{tabular}

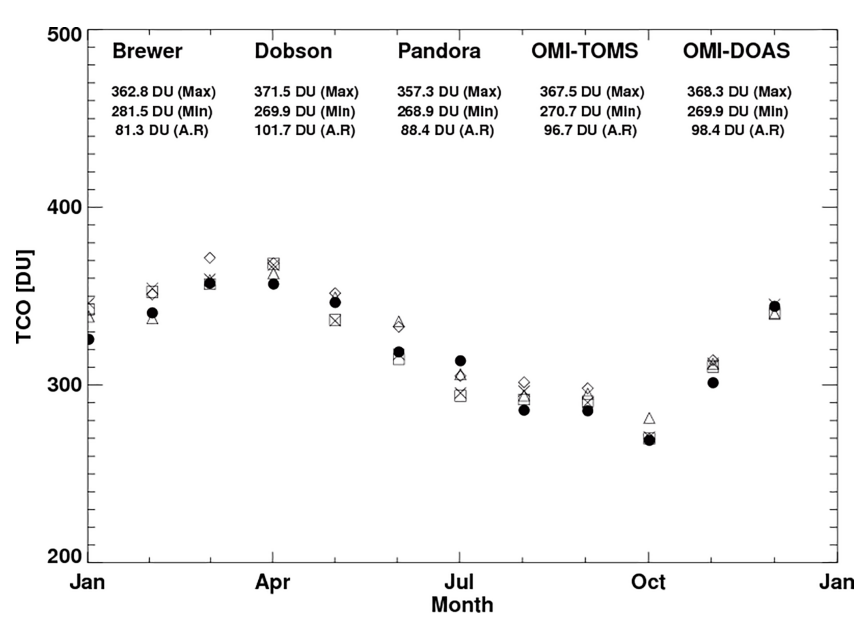

Figure 2. 2-year averaged monthly TCO values, together with the maximum, minimum values, and annual ranges (A.R) from the four instruments over the study period.

year average value of $317.2 \mathrm{DU}$, with a standard deviation of 36.8 DU and a maximum of 436.7 DU on 6 April 2012, and a minimum of $249.2 \mathrm{DU}$ on 7 October 2013. Figure 3 shows the histograms of all daily TCO data with their maximum frequency in the bin of 300-350 DU, where PAN provides a reasonable amount of sampling for the entire TCO ranges compared to other instruments. Based on the comparison result, the average TCO values of the PAN, DBS, BRE, and OMI instruments in Table 2 are a reliable representation over the 2-year period for each instrument. The annual mean TCO values from 2012 to 2014 are the largest for the DBS $(331.9 \pm 38.6 \mathrm{DU})$ and smallest for the PAN $(317.2 \pm 36.8 \mathrm{DU})$. The annual and monthly mean TCO values over this period are similar to past results, i.e., within $2 \%$ of the annual and monthly TCO values measured by DBS from 1985 to 2000, as presented by Cho et al. (2003).

\subsection{Intercomparisons of TCO measurements}

In this study, the linear least-squares regression method was used for all comparison results. To ensure high reliability of

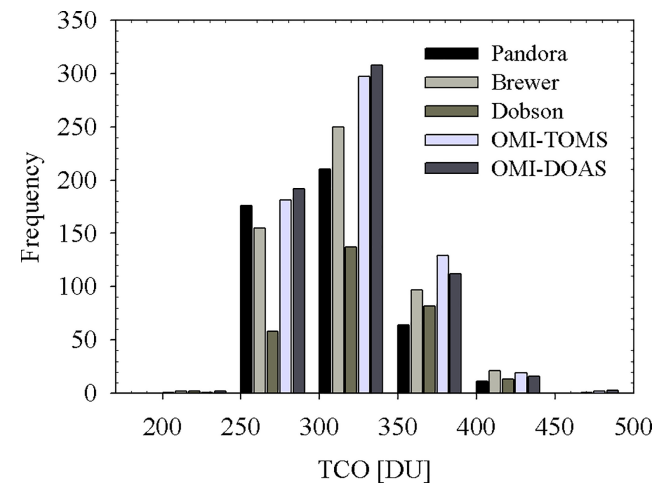

Figure 3. Histogram of daily TCO values from the four instruments (Pandora, Brewer, Dobson, and OMI (TOMS and DOAS)). Vertical axis (frequency) stands for the number of data in each TCO interval.

comparison results, only datasets in which complete data are available from all instruments were selected. To this end, prior to making the comparisons it was necessary to verify the accuracy of the datasets. Thus, intercomparisons of all available TCO values obtained from each instrument (except for PAN) were performed for the study period. As illustrated in Fig. 4, all of the regressions show excellent agreement, with slopes close to $1: 1$ and coefficient of determination $\left(R^{2}\right)$ greater than 0.90. In particular, the BRE shows results close to a perfect correlation with those of the DBS and OMI instruments, with slopes of 1.01 and 0.95 , and $R^{2}$ values of 1.00 and 0.97 (OMT), respectively. These strong correlations among the datasets indicate reliable measurements with high accuracies, thereby enabling a thorough regression analysis. Having established the reliability of the datasets, we next carried out the intercomparisons of the TCO values from PAN.

Figure 5 shows scatterplots of the daily TCO from PAN and those from DBS, BRE, and OMI, together with regression lines within an error range of $\pm 3 \%$ (Basher, 1985; Tzortziou et al., 2012) calculated by linear least-squares regression. The slope of the regression line and the coefficient of determination $\left(R^{2}\right)$ from the comparison of the PAN with the other instruments are both 0.95 for the DBS, 1.00 and 
(a)

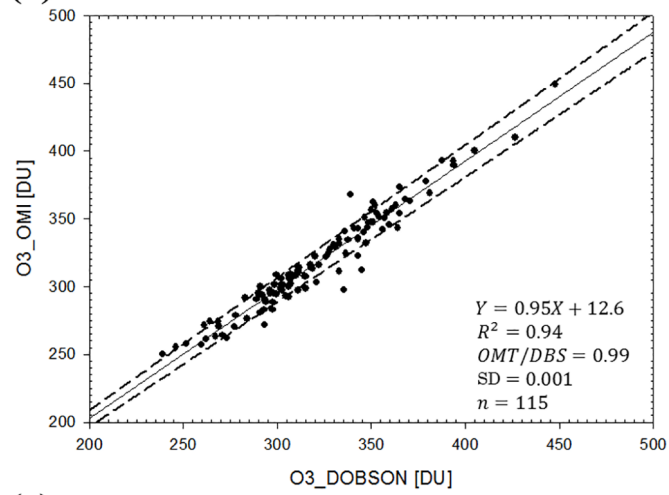

(c)

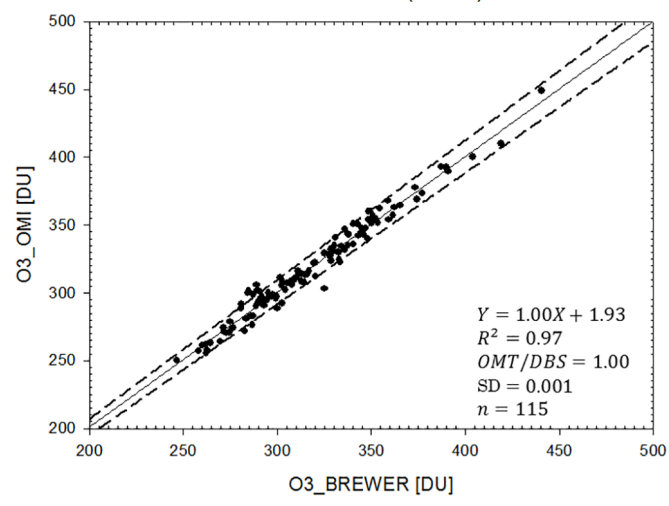

(e)

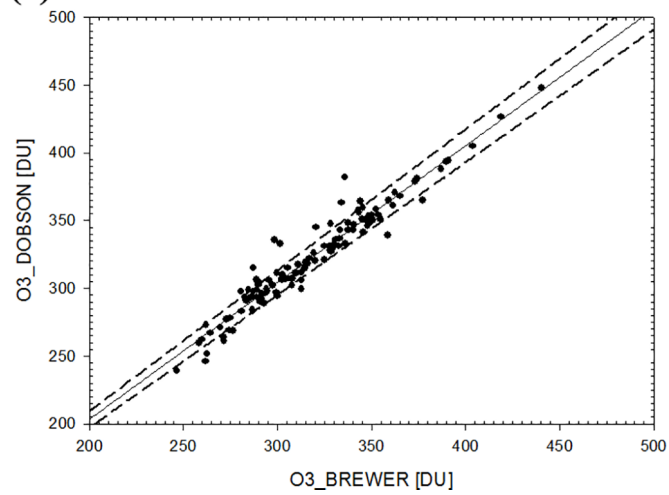

(b)

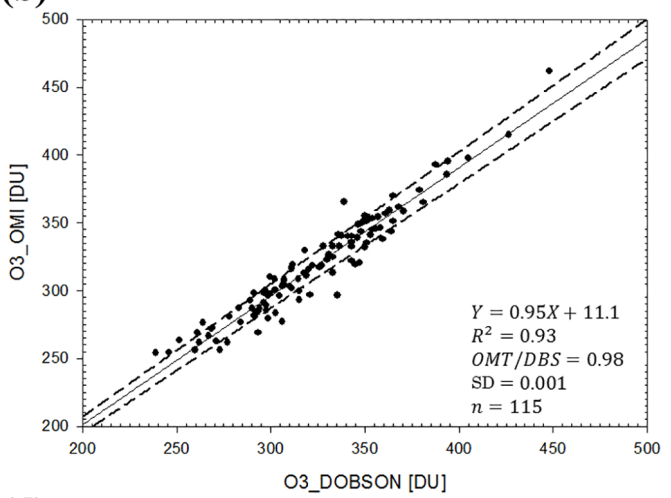

(d)

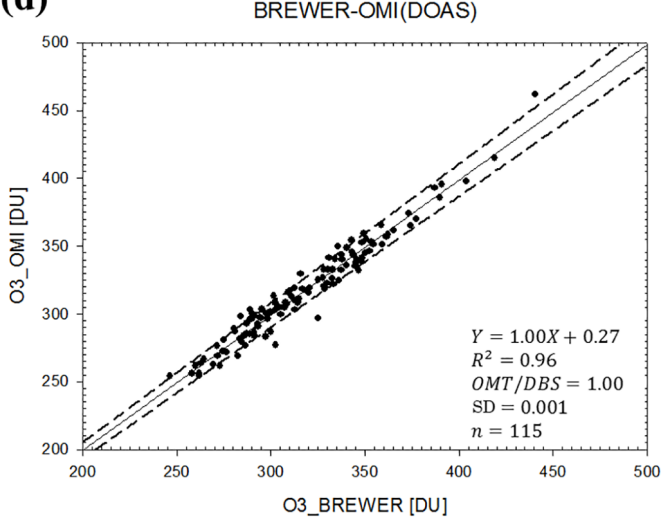

(f)

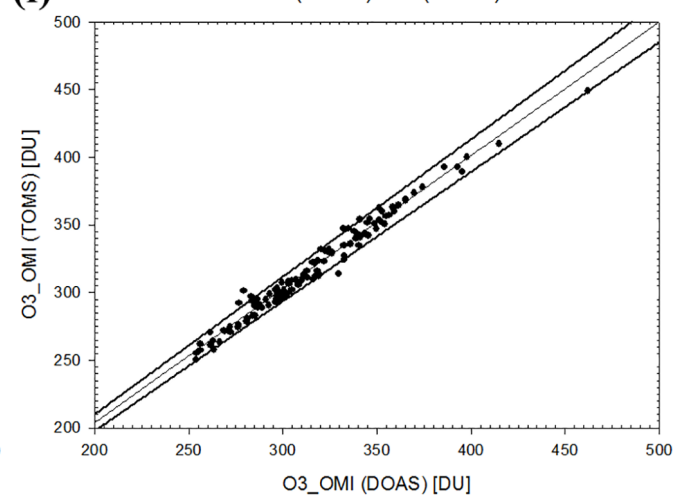

Figure 4. Intercomparison of daily TCO values between (a) Dobson (DBS) and OMI-TOMS (OMT), (b) Dobson (DBS) and OMI-DOAS (OMD), (c) Brewer (BRE) and OMI-DOAS (OMD), (e) Brewer (BRE) and Dobson (DBS), and (f) OMI-DOAS (OMD) and OMI-TOMS (OMT)

0.97 for the BRE, 0.98 and 0.96 for the OMT, and 0.97 and 0.95 for the OMD, respectively. That is, linear regression lines between PAN and all other instruments are very close to 1-to-1 line with very high correlation. Furthermore, the PAN shows the highest mean ratio value of $0.98 \pm 0.001( \pm 1 \sigma)$ with the BRE, which is slightly higher than the others. The mean ratio value is one of the parameters for intercomparison accuracy (e.g., Park et al., 2012). These high-correlation results are comparable with previous validation studies undertaken in Boulder, Colorado (Herman et al., 2015), and in
Greenbelt, Maryland (Tzortziou et al., 2012). Table 3 lists the mean relative differences, which are defined as the percentage differences between the observation data. All of these values show that the measured TCO values from the DBS, BRE, and OMI instruments are generally higher than those from the PAN. Figure 6 shows time series of the relative differences between the daily TCO values from the PAN and the other instruments, which is smallest between the OMD and PAN (2.01\% on average) but increases to $2.31,2.55$, and $3.64 \%$ for the BRE, OMT, and DBS data, respectively. 
(a)

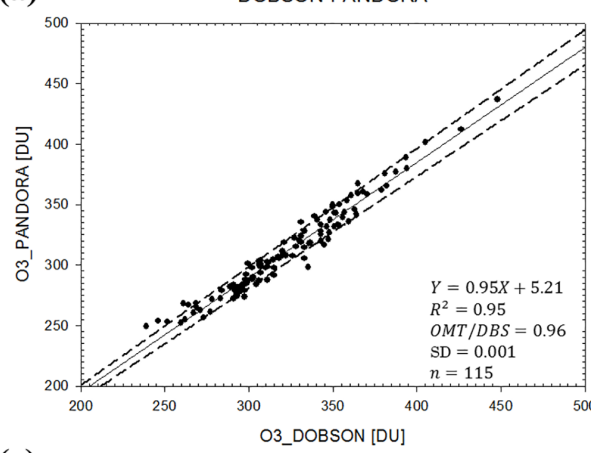

(c)

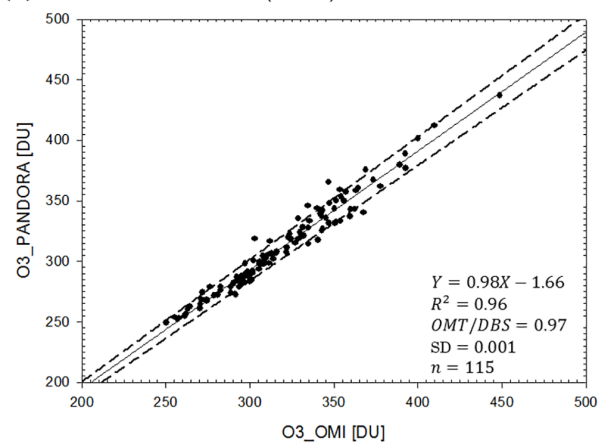

(b)

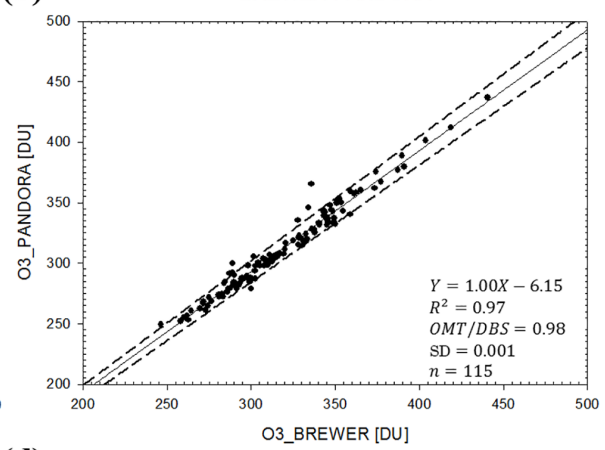

(d)

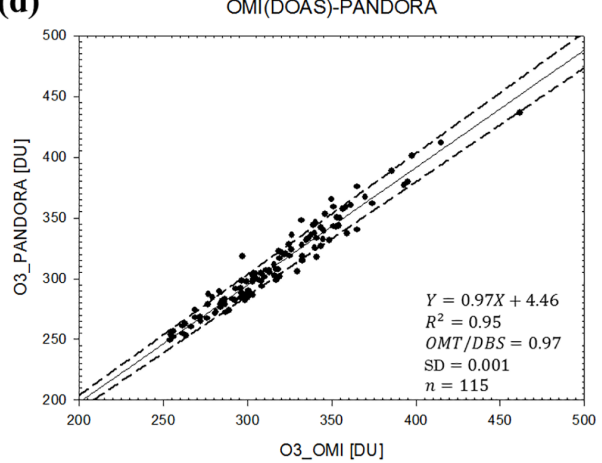

Figure 5. Intercomparison of daily TCO values from Pandora with Dobson (a), Brewer (b), and OMI (TOMS, c; DOAS, d). Solid lines represent regression lines, and dashed lines indicate an error range of $\pm 3 \%$.

(a)

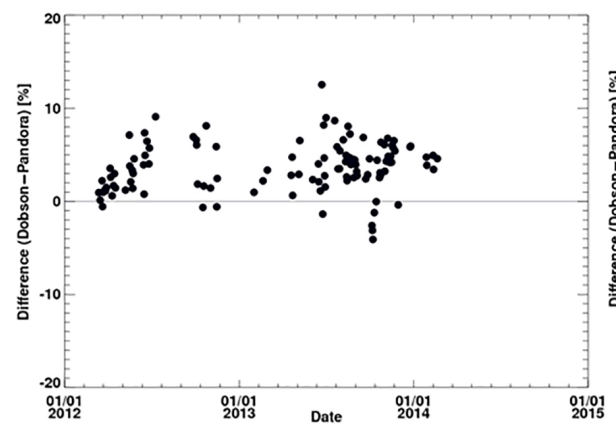

(c)

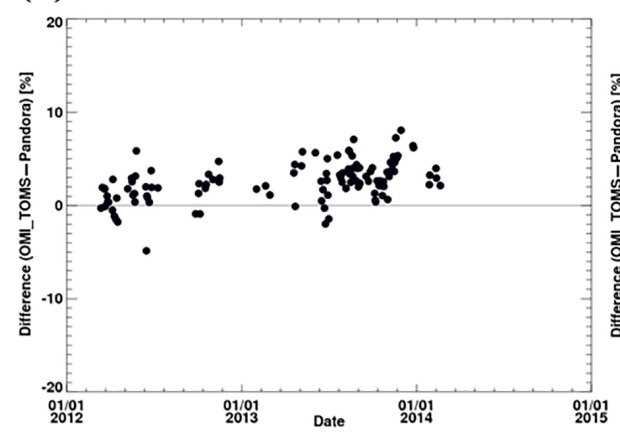

(b)

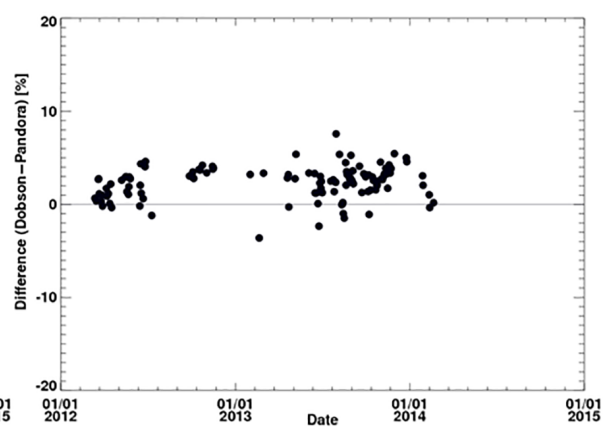

(d)

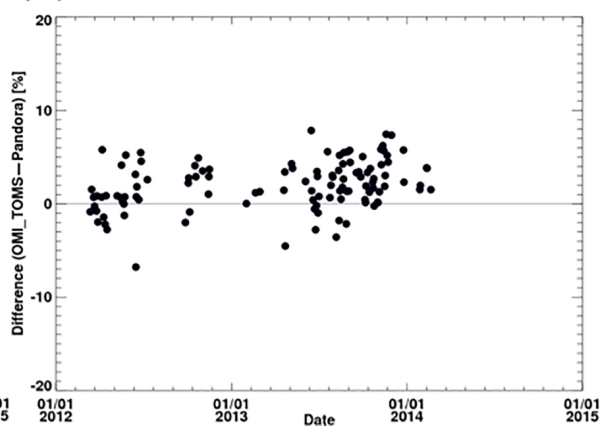

Figure 6. Time series of relative differences in daily TCO values from Pandora and those from (a) Dobson, (b) Brewer, (c) OMI-TOMS, and (d) OMI-DOAS ( $\left.\frac{\mathrm{TCO}_{\text {inst }}-\mathrm{TCO}_{\mathrm{Pan}}}{\mathrm{TCO}}[\%]\right)$. Gaps in the time series indicate at least one missing value in the observations from the four instruments. 
Table 3. ANOVA table for simple linear regression between the PAN and (a) DBS, (b) BRE, (c) OMT, and (d) OMD data. The column headings df, SS, MS, $F$, and $P$ stand for degrees of freedom, sum of squares, mean square, $F$ ratio, and $P$ value, respectively.

\begin{tabular}{|c|c|c|c|c|c|}
\hline (a) Source & df & SS & MS & $F$ & $P$ \\
\hline Total & 114 & 153,818 & & & \\
\hline Regression & 1 & 146765 & 146765 & 2351.5 & $<0.0001$ \\
\hline Residual (error) & 113 & 7053 & 62.4 & & \\
\hline Variable & Coefficient & s.e. & t ratio & & \\
\hline Intercept & 5.21 & 6.35 & 0.82 & & \\
\hline Slope & 0.95 & 0.02 & & & \\
\hline (b) Source & Df & SS & MS & $\mathrm{F}$ & $P$ \\
\hline Total & 114 & 153818 & & & \\
\hline Regression & 1 & 148,978 & 148,978 & 3477.9 & $<0.0001$ \\
\hline Residual (error) & 113 & 4840 & 42.8 & & \\
\hline Variable & Coefficient & s.e. & $\mathrm{t}$ ratio & & \\
\hline Intercept & -6.15 & 5.42 & -1.14 & & \\
\hline Slope & 1.00 & 0.02 & & & \\
\hline (c) Source & df & SS & MS & $\mathrm{F}$ & $P$ \\
\hline Total & 114 & 153,818 & & & \\
\hline Regression & 1 & 147429 & 147429 & 2607.4 & $<0.0001$ \\
\hline Residual (error) & 113 & 6389 & 56.5 & & \\
\hline Variable & Coefficient & s.e. & t ratio & & \\
\hline Intercept & -1.66 & 6.17 & -0.27 & & \\
\hline Slope & 0.98 & 0.02 & & & \\
\hline (d) Source & df & SS & MS & $\mathrm{F}$ & $P$ \\
\hline Total & 114 & 153818 & & & \\
\hline Regression & 1 & 145493 & 145493 & 1974.8 & $<0.0001$ \\
\hline Residual (error) & 113 & 8325 & 73.7 & & \\
\hline Variable & Coefficient & s.e. & t ratio & & \\
\hline Intercept & 4.46 & 6.95 & 0.64 & & \\
\hline Slope & 0.97 & 0.02 & & & \\
\hline
\end{tabular}

Based on these results, we conclude that the TCO data from the DBS, BRE, and OMI show reasonable agreement with the PAN.

We used a generic analysis of variance (ANOVA) table for simple linear regression to perform a more detailed analysis of these relationships. ANOVA tables for the comparisons are presented in Table 3, including the mean squared error (MSE), standard error (s.e.), and $F$ ratio, following the procedure of Wilks (2006). The MSE indicates the variability of the data, with a large MSE indicating a greater degree of scatter around the 1:1 line, and a small MSE the opposite. The MSE value for the comparison of PAN with BRE was the smallest (42.8), and it was the largest (73.7) with OMD, which means most data are located closest to the regression line between the PAN and BRE as shown in Fig. 5. The s.e. of the slope and the intercept represent the uncertainty of the regression line. The s.e. value of the slope was 0.02 for all comparisons with PAN, and that of the intercept was the smallest (5.42) and largest (6.95) for the comparisons with the BRE and OMD, respectively. Finally, the $F$ ratio (mean square regression (MSR) / MSE) increases with the strength of the regression (Draper et al., 1966; Neter et al., 1996). In Table 3, the $F$ ratio value calculated from the regression analysis of PAN with the BRE is 3477.9 , which is much greater than the others $(2351.5,2607.4$, and 1974.8 for DBS, OMT, and OMD, respectively). Taking all of these results into consideration, the TCO data measured by PAN are in the closest agreement with the BRE from the ANOVA analysis, similar to the validation results of Tzortziou et al. (2012).

The relatively small slopes, $R^{2}$, and $F$ ratios, and large MSE show that the PAN data have a slightly weaker linear relationship with the DBS and OMD data than with the BRE and OMT data (see Fig. 5 and Table 3). In particular, in the case of OMD, the regression result shows the smallest $R^{2}$ and $F$ ratio values of 0.95 and 1974.8 , respectively, and the largest MSE of 73.7, even though it has the small- 
est mean relative difference of $2.01 \%$. However, the time series of relative differences between the PAN and OMD TCO data in Fig. 6d shows more data points with negative relative difference than for the others, which are compensated with positive values. That is, for OMD, there are more and larger underestimated TCO values when compared with the PAN than for the DBS, BRE, and OMT, and these underestimated TCO values lead to the small mean relative difference. As a result, it is difficult to conclude that the TCO from the PAN and OMD are in good agreement only with a small mean relative difference value. Moreover, the largest MSE and smallest $F$ ratio values, which are used to assess the correlation between the PAN and OMD data, represent a poorer agreement among all intercomparison results, with an MSE of 73.7 and $F$ ratio of 1974.8 (Table 3d). In summary, the TCO from the PAN show a better correlation with those from the BRE or OMT data than with the OMD data. This result can be explained by the dependence of the OMD measurements on seasonal variations and SZA. According to previous studies, for a comparison between ground-based and OMI instruments, OMD data have a seasonal variation of about $\pm 2 \%$ and can be overestimated by $5 \%$ depending on SZA (Balis et al., 2007; Kroon et al., 2008; McPeters et al., 2008). The PAN shows very good agreement with the DBS, with a slope of 0.95 and $R^{2}$ of 0.95 . This result is similar to the findings of Herman et al. (2015), despite the following error sources in DBS and PAN measurements: (1) the limited amount of data used to calculate the single representative daily average by DBS; (2) the dependence on SZA, meaning that measurements are underestimated by $6 \%$ or overestimated by 20-30\% when SZAs are less than $57^{\circ}$ and greater than $60^{\circ}$, respectively (Bojkov, 1969; Komhyr, 1980; Miyagawa et al., 2005; Nichol and Valenti, 1993); (3) fixed effective temperature and high humidity, which lead to a bias in TCO retrievals (Herman et al., 2015; Komhyr, 1980); and (4) the $\mathrm{SO}_{2}$ absorption effect (De Backer and De Muer, 1991; Komhyr, 1980; Miyagawa et al., 2005);

According to Herman et al. (2015), both the standard TCO retrievals from DBS and PAN required a correction using a monthly varying effective ozone temperature for removing seasonal bias. They also showed that the TCO is dependent on the effective ozone temperature of -0.13 and $0.33 \% \mathrm{~K}^{-1}$ for Dobson and Pandora, respectively. Focusing on the effective ozone temperature, it is a potential error source for the comparison analysis. By fixing the effective ozone temperature, the potential discrepancy due to temperature is estimated to be $1 \%$ based on Table 1 . The $\mathrm{SO}_{2}$ absorption is not considered in DBS when using the two-wavelength pair method (AD pair), which overlaps the absorption by ozone on short UV wavelengths. Based on the absorption spectrum, the $\mathrm{SO}_{2}$ absorption affects the underestimation of TCO. For this reason, the TCO bias in DBS has a slight dependence on changing $\mathrm{SO}_{2}$ amounts (e.g., De Backer and De Muer, 1991). Hong et al. (2013) estimated the dependence of $\mathrm{SO}_{2}$ absorption in TCO by DBS to be $-1.64 \mathrm{DUDU}^{-1}\left(\mathrm{SO}_{2}\right)$. The $\mathrm{SO}_{2}$

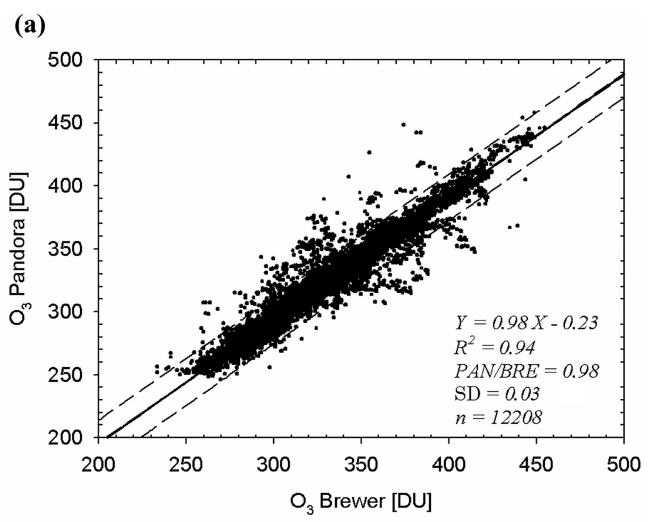

(b)

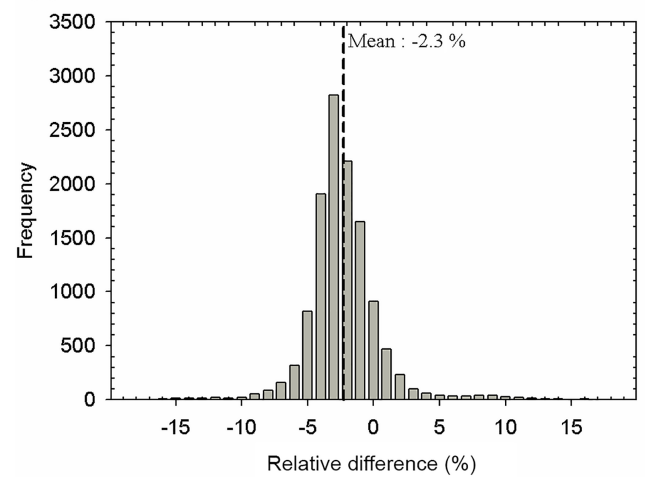

Figure 7. (a) Intercomparison of TCO amount and (b) histogram of relative difference between BRE and PAN based on the real-time data, with an observation time difference less than $5 \mathrm{~min}$.

data from OMI are up to 1.5 DU over northeastern China (Fioletov et al., 2013; Kroktov et al., 2008), which is upwind of Korea. However, the maximum monthly average of surface $\mathrm{SO}_{2}$ concentration is 0.007 ppm in January in Seoul, Korea (NIER, 2014), which corresponds to $\sim 0.6$ DU assuming constant mixture within planetary boundary layer height of $1 \mathrm{~km}$. By adopting these $\mathrm{SO}_{2}$ levels, the TCO error due to the $\mathrm{SO}_{2}$ can be up to $1 \%$.

\subsection{Instantaneous comparison of TCO between Pandora and Brewer}

Figure 7 shows the instantaneous comparison of TCO data between PAN and BRE based on their continuous observation, which is the most suitable dataset for detecting diurnal variation. For the comparison, the time difference between two instruments is within $5 \mathrm{~min}$. From Fig. 7a, the ratio between PAN and BRE is 0.98, which is the same value based on the daily comparison as shown in Fig. 5b, with a standard deviation of 0.03 . The standard deviation is an order of magnitude higher than those from the daily comparison. In addition, the slope and $R^{2}$ are also similar to the results from daily comparison, 0.98 for slope and 0.94 for $R^{2}$. Figure $7 \mathrm{~b}$ shows the histogram for relative difference of TCO between the two instruments, and the proportion of relative difference 


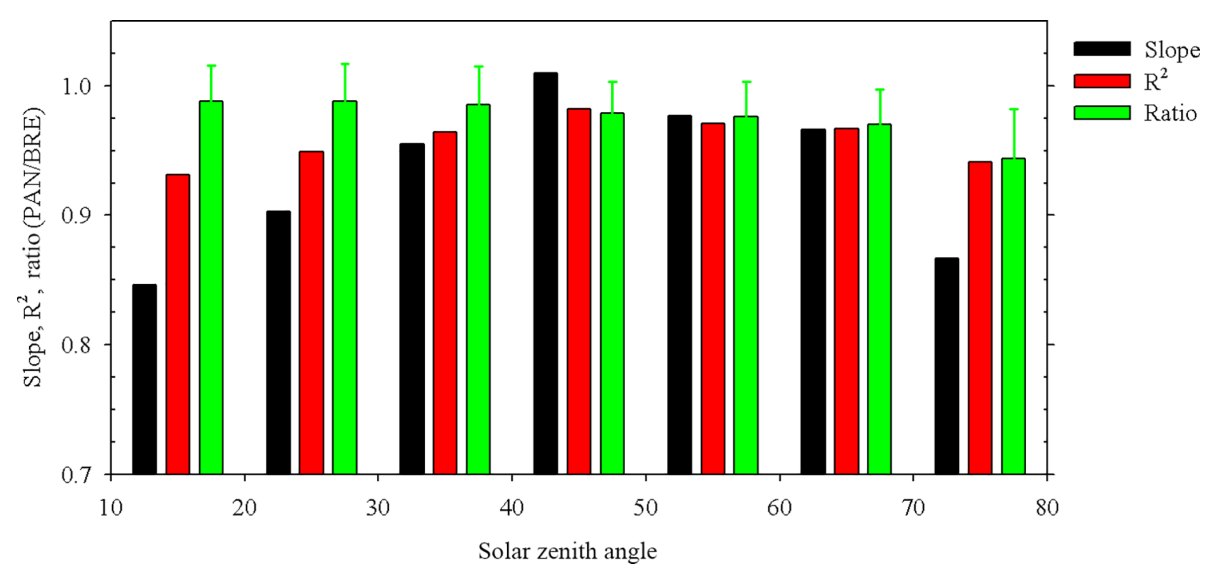

Figure 8. Slope, $R^{2}$, and the ratio value for the real-time data between BRE and PAN with respect to the SZA change.

smaller than 5 and $3 \%$ is $89.2 \%$ (10891 of 12208 data) and $57.1 \%$ (6965 of 12208 data), respectively. As shown in Fig. 7, the relative difference represents normal distribution with weak bias and coincided with the standard deviation of TCO.

Figure 8 shows the slope and $R^{2}$ of regression and the ratio of TCO between BRE and PAN with respect to the SZA to see the dependence on observation geometry. The statistical results are slightly correlated to the SZA. Both the slope and $R^{2}$ are the lowest at SZAs of $10-20^{\circ}$ and the highest at SZAs of $40-50^{\circ}$. The lowest slope and $R^{2}$ at SZAs of $10-20^{\circ}$ is related to the seasonal characteristics. Most of the data with a SZA of $10-30^{\circ}$ correspond to observation in summer, which is frequently obstructed by the cloudy and highmoisture conditions due to the Asian summer monsoon. Otherwise, for the SZA of $70-80^{\circ}$ (effectively $70-75^{\circ}$ due to data selection of PAN) the comparison shows a low ratio value with a low slope and $R^{2}$. The ratio value in this SZA range is 0.944 with a standard deviation of 0.038 , while those at other SZAs are 0.970-0.988. For the high-SZA cases, observations are more sensitive to the scattering due to aerosol than the low-SZA cases, and the radiance is diminished due to the long optical path length. These characteristics by optical geometry partially affect reducing sensitivity of TCO retrieval in both BRE and PAN. In addition, Zhao et al. (2016) analyzed that PAN data have negligible air mass dependence when the ozone $\mathrm{AMF}<3$. For the large-AMF cases, the stray-light effect in the instrument detector affects the accuracy of total ozone retrieval (Herman et al., 2015; Tzortziou et al., 2012) with its dependence on slant column amounts of ozone. In Seoul, this stray-light effect for SZA $>70^{\circ}$ results in the underestimation of TCO in Pandora by about $3 \%$, although this comparison study uses the fitting error control and SZA $<75^{\circ}$. Because the number of observation data for this SZA range is 189 , which is much smaller than for other SZAs, TCO differences in high SZA still require further analysis to explain the details of the underestimation.

\subsection{Diurnal variations in Pandora TCO}

As mentioned above, the temporal resolution of the PAN is about $2 \mathrm{~min}$, which allows us to detect diurnal variations of TCO. Figure 9 shows six cases of diurnal variation for the TCO values measured by the PAN with average, minimum, and maximum values under clear-sky condition when the cloud amount is less than $3 / 10$ during the study period. In this figure, TCO data measured at SZAs greater than $75^{\circ}$ are shaded and excluded from the statistical calculations, as mentioned in Sect. 2.5. According to Herman et al. (2015), the Pandora (no. 34) TCO data measured at Boulder, Colorado, over 13 consecutive days in December 2013 showed considerable variations. Similarly, in Fig. 9 there are substantial daytime variations for all six cases, especially on 5 March 2013 (Fig. 9c), which shows the largest standard deviation of 15.4 DU. Moreover, the range of TCO values on a given day shows a largest value of $53.4 \mathrm{DU}$, about $15.3 \%$ of the daily average value. Because of these variations, the inconsistency of time intervals between measurements selected for the daily averaging in the intercomparison can result in a sampling bias. In particular, DS observations by the DBS have been performed typically at most three times a day. Observation times and real-time TCO values, as well as the daily average values of the DBS, are shown for each diurnal cycle in Fig. 9. In the six cases, the daily TCO values from the PAN were underestimated by about $5 \%$ compared with those of the DBS. For the entire period, the maximum difference between the daily TCO values of the PAN and DBS was $\sim 12.5 \%$ on 22 June 2013 . Herman et al. (2015) suggested that the time interval from PAN for comparison with DBS should be kept fairly short (e.g., 8 min) to avoid undersampling of the coincident time series. 
(a)

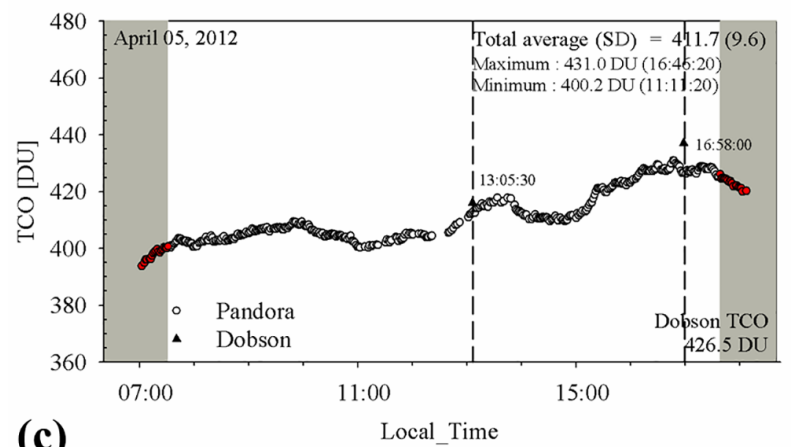

(c)

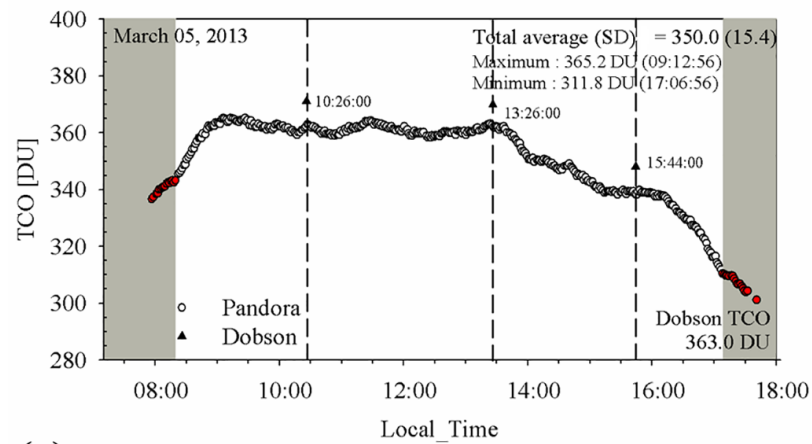

(e)

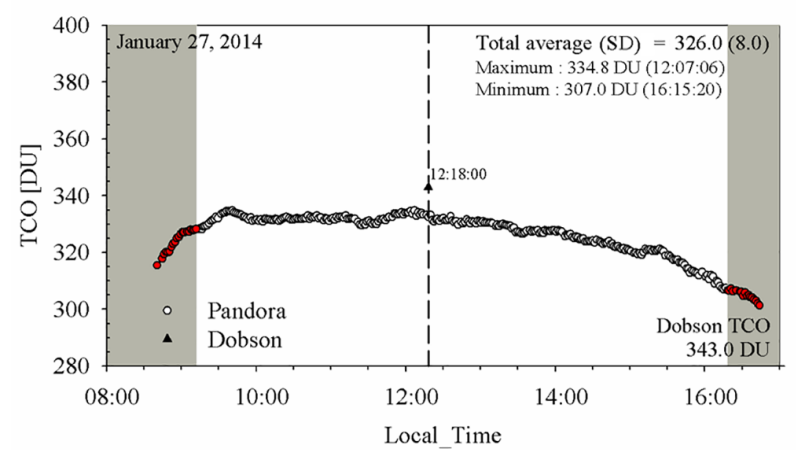

(b)
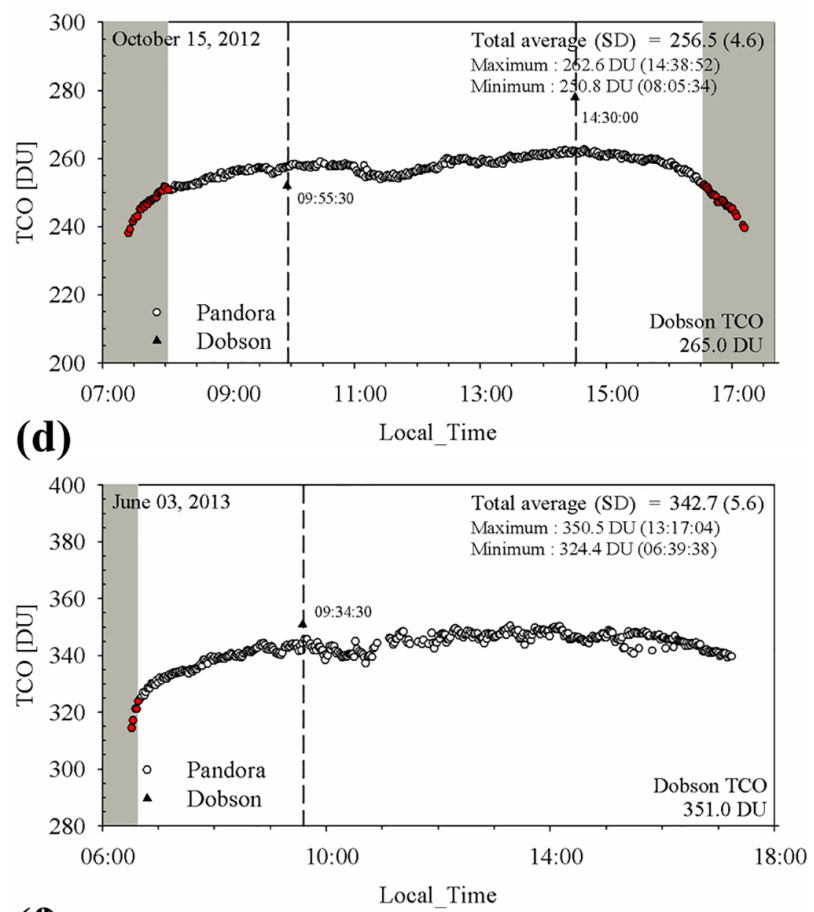

(f)

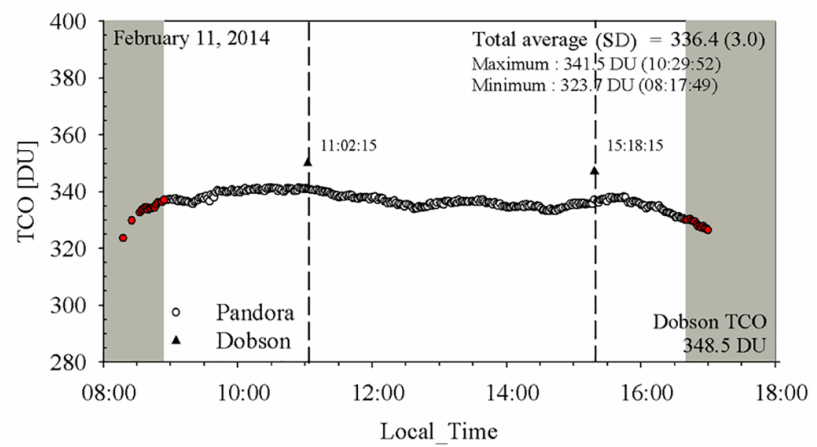

Figure 9. Diurnal variations in TCO values retrieved from Pandora for six randomly selected clear-sky days (cloud amount $<3$ ) during the study period. TCO values measured at solar zenith angle $>75^{\circ}$ are shaded and were removed from the calculations. Filled circles and dashed lines represent direct-sun TCO values measured by the Dobson instrument and observation times, respectively. All vertical axes have the same scale range of $100 \mathrm{DU}$.

\section{Summary and discussion}

In this study, daily total ozone data measured by the Pandora spectrophotometer were compared using ground-based and satellite measurements (DBS, BRE, and OMI) over a 2-year period at Yonsei University, Seoul, Korea. A linear least-squares regression analysis revealed that the Pandora TCO data show excellent agreement with other instruments, with slopes close to 1 and $R^{2}$ greater than 0.95 , which are within $\pm 5 \%$ of perfect regression. In addition, comparison of the mean relative differences shows that the Pandora TCO data were underestimated compared to other instruments. Through detailed comparison using the ANOVA approach, we found that the regression of the Pandora with the BRE data shows the smallest MSE value of 42.8 and the largest $F$ ratio of 3477.9, indicating a close relationship. Several internal and external factors result in slight differences between the Pandora measurements and other data, i.e., the time interval difference for daily averaging, dependence on SZA, $\mathrm{SO}_{2}$ effect, effective ozone temperature, instrumental humidity for the DBS data, and dependence on seasonal variations and SZA for the OMD data. In particular, the Pandora measurements were underestimated by up to about $12.5 \%$ compared with the TCO obtained from the DBS on 22 June 2013. Despite these factors, daily TCO values retrieved from Pandora showed very good agreement. 
The Pandora spectrophotometer is also useful for measuring diurnal variation of TCO by comparing the real-time data with the BRE. Although TCO values at large SZAs have slightly increasing differences, real-time TCO values also have high levels of confidence in the analysis of diurnal variation. Consequently, daily and real-time total ozone data measured by the Pandora spectrophotometer show high reliability and are expected to improve substantially with the regular, accurate calibration and validation associated with the operational monitoring of trace gases and pollutants. The underestimation of PAN TCO in long-optical-path-length cases in Seoul can be attributed to the enhancement of aerosol scattering and the stray-light effect of the instrument, which is similar to previous comparison studies in Herman et al. (2015) and Zhao et al. (2016). However, detailed reasons for TCO underestimation for large SZAs still require further studies.

Data availability. For the total column ozone data, the daily representative data for Dobson measurements in Seoul are available from WOUDC/GO3OS (http://www.woudc.org). In addition, we thank the OMI team for providing the valuable satellite dataset, which can be accessed at http://mirador.gsfc.nasa.gov/. For the Brewer observation data, please contact Yonsei University.

Competing interests. The authors declare that they have no conflict of interest.

Acknowledgements. This research was supported by the GEMS program of the South Korean Ministry of Environment and the Eco Innovation Program of KEITI (2012000160002). Authors appreciate the continuous site operation support of the Dobson and Brewer spectrophotometers at Yonsei University from the Korea Meteorological Administration (KMA). Authors also would like to express appreciation for the valuable satellite dataset from the OMI team.

Edited by: Erna Frins

Reviewed by: three anonymous referees

\section{References}

Antón, M., Lopez, M., Vilaplana, J. M., Kroon, M., McPeters, R., Banon, M., and Serrano, A.: Validation of OMI-TOMS and OMIDOAS total ozone column using five Brewer spectroradiometers at the Iberian peninsula, J. Geophys. Res., 114, D14307, https://doi.org/10.1029/2009jd012003, 2009.

Angell, J. K.: On the Relation between atmospheric ozone and Sunspot number, J. Climate, 2, 1404-1416, 1989.

Appenzeller, C., Weiss, A. K., and Staehelin, J.: North Atlantic Oscillation modulates total ozone winter trends, Geophys. Res. Lett., 27, 1131-1134, https://doi.org/10.1029/1999GL010854, 2000 .
Balis, D., Kroon, M., Koukouli, M. E., Brinksma, E. J., Labow, G., Veefkind, J. P., and McPeters, R. D.: Validation of Ozone Monitoring Instrument total ozone column measurements using Brewer and Dobson spectrophotometer ground-based observations, J. Geophys. Res., 112, https://doi.org/10.1029/2007jd008796, 2007.

Basher, R. E.: Review of the dobson spectrophotometer and its accuracy, in: Atmospheric Ozone, edited by: Zerefos, C. S. and Ghazi, A., Reidel and Dordrect, 387 pp., 1985.

Bass, A. M. and Paur, R. J.: The Ultraviolet Cross-Sections of Ozone: Part I. The Measurements, edited by: Zerefos, S., Hazi, A., and Reidel, D., Halkidiki Greece, Proceedings of the Quadrennial Ozone Symposium on Atmospheric Ozone, Norwell, 606-610, 1985.

Bhartia, P. and Wellemeyer, C.: OMI TOMS-V8 Total $\mathrm{O}_{3}$ algorithm, algorithm theoretical baseline document: OMI ozone products, Bhartia, P. K., Vol. II, ATBD-OMI-02, version 2.0, 2002.

Bojkov, R. D.: Differences in Dobson spectrophotometer and filter ozonometer measurements of total ozone, J. Appl. Meteorol., 8, 362-368, 1969.

Brewer, A.: Evidence for a world circulation provided by the measurements of helium and water vapour distribution in the stratosphere, Q. J. Roy. Meteor. Soc., 75, 351-363, 1949.

Brewer, A.: A replacement for the Dobson spectrophotometer?, Pure Appl. Geophys., 106, 919-927, 1973.

Brion, J., Chakir, A., Daumont, D., Malicet, J., and Parisse, C.: High-resolution laboratory absorption cross section of $\mathrm{O}_{3}$ Temperature effect, Chem. Phys. Lett., 213, 610-612, 1993.

Brion, J., Chakir, A., Charbonnier, J., Daumont, D., Parisse, C., and Malicet, J.: Absorption spectra measurements for the ozone molecule in the 350-830 nm region, J. Atmos. Chem., 30, 291299, 1998.

Buchard, V., Brogniez, C., Auriol, F., Bonnel, B., Lenoble, J., Tanskanen, A., Bojkov, B., and Veefkind, P.: Comparison of OMI ozone and UV irradiance data with ground-based measurements at two French sites, Atmos. Chem. Phys., 8, 4517-4528, https://doi.org/10.5194/acp-8-4517-2008, 2008.

Cede. A.: Manual for Pandora Software Suite Version 1.6, August, 2013, available at: http://avdc.gsfc.nasa.gov/pub/tools/Pandora/ install/ (last access: 28 September 2017), 2013.

Cho, H.: Ozone layer monitoring over Korea, 1985-1994, Global Environment Laboratory, Yonsei University, 224 pp., 1996.

Cho, H., Lee, S., and Choi, C.: The seasonal variations of total ozone at Seoul, Journal of Korean Meteorology, 25, 21-29, 1989.

Cho, H.-K., Kim, J., Oh, S. N., Kim, S.-K., Baek, S.-K., and Lee, Y. G.: A climatology of stratospheric ozone over Korea, Korean Journal of the Atmospheric Sciences, 6, 97-112, 2003.

Chubachi, S.: A special ozone observation at Syowa Station, Antarctica from February 1982 to January 1983, in: Atmospheric ozone, Springer, 285-289, 1985.

Creilson, J. K., Fishman, J., and Wozniak, A. E.: Arctic oscillation-induced variability in satellite-derived tropospheric ozone, Geophys. Res. Lett., 32, L14822, https://doi.org/10.1029/2005GL023016, 2005.

Daumont, D., Brion, J., Charbonnier, J., and Malicet, J.: Ozone UV spectroscopy: Absorption cross-sections at room temperature, J. Atmos. Chem., 15, 145-155, 1992. 
Dave, J.: Meaning of Successive Iteration of the Auxiliary Equation in the Theory of Radiative Transfer, Astrophys. J., 140, 12921303, 1964.

De Backer, H. and De Muer, D.: Intercomparison of total ozone data measured with Dobson and Brewer ozone spectrophotometers at Uccle (Belgium) from January 1984 to March 1991, including zenith sky observations, J. Geophys. Res.-Atmos., 96, 2071120719, 1991.

Dobson, G. M. B.: Forty years' research on atmospheric ozone at Oxford: a history, Appl. Optics, 7, 387-405, 1968.

Draper, N. R., Smith, H., and Pownell, E.: Applied regression analysis, Wiley New York, 1966.

Duetsch, H. U.: Vertical ozone distribution from Umkehr observations, Meteorol. Atmos. Phys., 11, 240-251, 1959.

Evans, R. D. and Komhyr, W. D.: Operations Handbook - Ozone Observations with A Dobson Spectrophotometer, World Meteorological Organization Global AtmosphereWatch GAWNo.183, WMO/TD-No. 1469, 2008.

Farman, J., Gardiner, B., and Shanklin, J.: Large losses of total ozone in Antarctica reveal seasonal $\mathrm{ClO}_{x} / \mathrm{NO}_{x}$ interaction, Nature, 315, 207-210, 1985.

Fioletov, V. E., Bodeker, G. E., Miller, A. J., Mc Peters, R. D., and Stolarski, R.: Global and zonal total ozone variations estimated from ground-based and satellite measuerements: 1964-2000, J. Geophys. Res., 107, 4647, https://doi.org/10.1029/2001JD001350, 2002.

Fioletov, V. E., McLinden, C. A., Krotkov, N., Yang, K., Loyola, D. G., Valks, P., Theys, N., Van Roozendael, M., Nowlan, C. R., Chance, X. Liu, C., Lee, R., and Martin, V.: Application of OMI, SCIAMACHY, and GOME-2 satellite $\mathrm{SO}_{2}$ retrievals for detection of large emission sources, J. Geophys. Res.-Atmos., 118, 11399-11418, https://doi.org/10.1002/jgrd.50826, 2013.

Goetz, F. W. P., Meetham, A. R., and Dobson, G. M. B.: The vertical distribution of ozone in the Atmosphere, P. R. Soc. Lond. A, 145, 416-446, 1934.

Harris, N., Ancellet, G., Bishop, L., Hofmann, D., Kerr, J., McPeters, R., Prendez, M., Randel, W., Staehelin, J., and Subbaraya, B.: Trends in stratospheric and free tropospheric ozone, J. Geophys. Res.-Atmos., 102, 1571-1590, 1997.

Harris, N. R. P., Ancellet, G., Bishop, L., Hofmann, D. J., Kerr, J. B., McPeters, R. D., Prendez, M., Randel, W. J., Staehelin, J., Subbaraya, B. H., Volz-Thomas, A., Zawodny, J., and Zerefos, C. S.: Trends in stratospheric and free tropospheric ozone, J. Geophys. Res., 102, 1571-1590, https://doi.org/10.1029/96JD02440, 2003.

Hwang, S.-H., Kim, J., and Cho, G.-R.: Observation of secondary ozone peaks near the tropopause over the Korean peninsula associated with stratospheretroposphere exchange, J. Geophys. Res., 112, D16305, https://doi.org/10.1029/2006JD007978, 2007.

Herman, J., Cede, A., Spinei, E., Mount, G., Tzortziou, M., and Abuhassan, N.: $\mathrm{NO}_{2}$ column amounts from groundbased Pandora and MFDOAS spectrometers using the direct-sun DOAS technique: Intercomparisons and application to OMI validation, J. Geophys. Res., 114, D13307, https://doi.org/10.1029/2009jd011848, 2009.

Herman, J., Evans, R., Cede, A., Abuhassan, N., Petropavlovskikh, I., and McConville, G.: Comparison of ozone retrievals from the Pandora spectrometer system and Dobson spectrophotome- ter in Boulder, Colorado, Atmos. Meas. Tech., 8, 3407-3418, https://doi.org/10.5194/amt-8-3407-2015, 2015.

Hong, H., Kim, J., Lee, H., and Cho, H. K.: Inter-comparison of Total ozone from the Ground-based and Satellite Measurements at Seoul, Atmosphere-KMS, 23, 123-130, 2013.

Hong, H., Lee, H., Kim, J., and Lee, Y.-G.: First comparison of OMI-DOAS total ozone using ground-based observations at a megacity site in East Asia: Causes of discrepancy and improvement in OMI-DOAS total ozone during summer, J. Geophys. Res.-Atmos., 119, 10058-10067, https://doi.org/10.1002/2014jd021829, 2014.

Kerr, J.: New methodology for deriving total ozone and other atmospheric variables from Brewer spectrophotometer direct sun spectra, J. Geophys. Res.-Atmos., 107, 4731, https://doi.org/10.1029/2001JD001227, 2002.

Kerr, J.: The Brewer Spectrophotometer, in: UV Radiation in Global Climate Change, Springer, 160-191, 2010.

Kerr, J., McElroy, C., Wardle, D., Olafson, R., and Evans, W.: The automated Brewer spectrophotometer, in: Atmospheric Ozone, Springer, 396-401, 1985.

Kim, J., Cho, H., Lee, Y., Oh, S., and Baek, S.: Updated trends of stratospheric ozone over Seoul, Atmosphere, 15, 101-118, 2005.

Kim, J., Park, S., Moon, K., Koo, J., Lee, Y., Miyagawa, K., and Cho, H.: Automation of Dobson spectrophotometer (No. 124) for ozone measurements, Atmos. Korean Meteor. Soc, 17, 339-348, 2007.

Kim, J., Park, S., Cho, N., Kim, W., and Cho, H. K.: Recent Variations of UV Irradiance at Seoul 2004-2010, Atmosphere, 21, 429-438, 2011.

Kim, W., Kim, J., Park, S. S., and Cho, H.-K.: UV Sensitivity to Changes in Ozone, Aerosols, and Clouds in Seoul, South Korea, J. Appl. Meteorol. Clim., 53, 310-322, https://doi.org/10.1175/jamc-d-13-052.1, 2014.

Komhyr, W.: Operations handbook-Ozone observations with a Dobson spectrophotometer, NOAA Environmental Research Laboratories, Air Resources Laboratory, 1980.

Kroon, M., Veefkind, J. P., Sneep, M., McPeters, R., Bhartia, P., and Levelt, P.: Comparing OMI-TOMS and OMI-DOAS total ozone column data, J. Geophys. Res.-Atmos., 113, D16S28, https://doi.org/10.1029/2007JD008798, 2008.

Kroktov, N. A., McClure, B., Dickerson, R. R., Carn, S. A., Li, C., Bhartia, P. K., Yang, K., Krueger, A. J., Li, Z., Levelt, P. F., Chen, H., Wang, P., and Lu, D.: Validation of $\mathrm{SO}_{2}$ retrievals from the Ozone Monitoring Instrument over NE China, J. Geophys. Res., 113, D16S40, https://doi.org/10.1029/2007JD008818, 2008.

Leonard, R.: Dobson spectrophotometer 83: A standard for total ozone measurements, 1962-1987, J. Geophys. Res., 94, $9847-$ 9861, 1989.

Levelt, P. F., Van den Oord, G. H., Dobber, M. R., Malkki, A., Visser, H., De Vries, J., Stammes, P., Lundell, J. O., and Saari, H.: The ozone monitoring instrument, IEEE T. Geosci. Remote Sens., 44, 1093-1101, 2006.

Liou, K. N.: An introduction to to atmospheric radiation, Vol. 84, Academic press, 2002.

Malicet, J., Daumont, D., Charbonnier, J., Parisse, C., Chakir, A., and Brion, J.: Ozone UV spectroscopy, II. Absorption crosssections and temperature dependence, J. Atmos. Chem., 21, 263 273, 1995. 
Martens, W.: Health impacts of climate change and ozone depletion: an ecoepidemiologic modeling approach, Environ. Health Persp., 106, 241-251, 1998.

McPeters, R., Kroon, M., Labow, G., Brinksma, E., Balis, D., Petropavlovskikh, I., Veefkind, J. P., Bhartia, P. K., and Levelt, P. F.: Validation of the Aura Ozone Monitoring Instrument total column ozone product, J. Geophys. Res., 113, D15S14, https://doi.org/10.1029/2007jd008802, 2008.

Miyagawa, K., Kim, J., and Cho, H.: Intercomparison of Dobson Spectrophotometer in Yonsei Univ., Korea, Journal of Aerological Observatory, 65, 93-98, 2005.

Neter, J., Kutner, M. H., Nachtsheim, C. J., and Wasserman, W.: Applied linear statistical models, Chicago, McGraw-Hill/Irwin, 1996.

Newchurch, M., Yang, E. S., Cunnold, D., Reinsel, G. C., Zawodny, J., and Russell, J. M.: Evidence for slowdown in stratospheric ozone loss: First stage of ozone recovery, Journal of Geophysical Research: Atmospheres, 108, 2003.

Nichol, S. and Valenti, C.: Intercomparison of total ozone measured at low sun angles by the Brewer and Dobson spectrophotometers at Scott Base, Antarctica, Geophys. Res. Lett., 20, 2051-2054, 1993.

NIER (National Institute of Environmental Research): Annual Report of Air Quality in Korea 2014, 259 pp., 2014.

Park, S. S., Kim, J., Cho, H. K., Lee, H., Lee, Y., and Miyagawa, K.: Sudden increase in the total ozone density due to secondary ozone peaks and its effect on total ozone trends over Korea, Atmos. Environ., 47, 226-235, https://doi.org/10.1016/j.atmosenv.2011.11.011, 2012.

Petropavlovskikh, I., Bhartia, P. K., and DeLuisi, J.: New Umkehr ozone profile retrieval algorithm optimized for climatological studies, Geophys. Res. Let., 34, L16808, https://doi.org/10.1029/2005GL023323, 2005.

Platt, U. and Stutz, J.: Differential absorption spectroscopy, Springer, Berlin, Heidelberg, 2008.

Reed, A. J., Thompson, A. M., Kollonige, D. E., Martins, D. K., Tzortziou, M. A., Herman, J. R., Berkoff, T. A., Abuhassan, N. K., and Cede, A.: Effects of local meteorology and aerosols on ozone and nitrogen dioxide retrievals from OMI and pandora spectrometers in Maryland, USA during DISCOVER-AQ 2011, J. Atmos. Chem., 72, 455-482, 2015.

Reinsel, G. C. and Tiao, G. C.: Impact of chlorofluoromethanes on stratospheric ozone: a Statistical analysis of ozone data and trends, J. Am. Stat. Assoc., 82, 20-30, 1987.

Reinsel, G., Tiao, G. C., Wang, M. N., Lewis, R., and Nychka, D.: Statistical analysis of stratospheric ozone data for the detection of trends, Atmos. Environ., 15, 1569-1577, 1981.

Reinsel, G. C., Miller, A. J., Weatherhead, E. C., Flynn, L. E., Nagatani, R. M., Tiao, G. C., and Wuebble, D. J.: Trend analysis of total ozone data for turnaround and dynamical contributions, J. Geophys. Res., 110, D16306, https://doi.org/10.1029/2004JD004662, 2005.

Sabburg, J., Rives, J. E., Meltzer, R. S., Taylor, T., Schmalzle, G., Zheng, S., Huang, N., Wilson, A., and Udelhofen, P. M.: Comparisons of corrected daily integrated erythemal UVR data from the U.S. EPA/UGA network of Brewer spectroradiometers with model and TOMS-inferred data, J. Geophys. Res.-Atmos., 107, ACL5-1-ACL5-10, https://doi.org/10.1029/2001jd001565, 2002.
Schott, J. R.: Remote Sensing, Oxford University Press, 2007.

Solomon, S.: Stratospheric ozone depletion: A review of concepts and history, Rev. Geophys., 37, 275-316, 1999.

Solomon, S., Ivy, D. J., Kinnison, D., Mills, M. J., Neely III, R. B., and Schmidt, A.: Emergence of healing in the Antarctic ozone layer, Science, 353, 269-274, https://doi.org/10.1126/science.aae0061, 2016.

Stolarski, R. S. and Frith, S. M.: Search for evidence of trend slowdown in the long-term TOMS/SBUV total ozone data record: the importance of instrument drift uncertainty, Atmos. Chem. Phys. 6, 4057-4065, https://doi.org/10.5194/acp-6-4057-2006, 2006.

Stolarski, R. S., Bloomfield, P., and McPeters, R. D.: Total Ozone trends deduced from NIMBUS 7 TOMS Data, Geophys. Res. Lett., 18, 1015-1018, 1991.

Tzortziou, M., Herman, J. R., Cede, A., and Abuhassan, N.: High precision, absolute total column ozone measurements from the Pandora spectrometer system: Comparisons with data from a Brewer double monochromator and Aura OMI, J. Geophys. Res.Atmos., 117, D16303, https://doi.org/10.1029/2012jd017814, 2012.

Veefkind, J. P., De Haan, J. F., Brinksma, E. J., Kroon, M., and Levelt, P. F.: Total ozone from the Ozone Monitoring Instrument (OMI) using the DOAS technique, IEEE T. Geosci. Remote Sens., 44, 1239-1244, 2006.

Wang, Y., Zhao, P., Xu, H., and Liu, G.: Anomalies of Northern Hemisphere ozone associated with a tropopause-lower stratosphere teleconnection during summer, Int. J. Climatol., 36, 837846, 2015.

Weatherhead, E. C., Reinsel, G. C., Tiao, G. C., Jackman, C. H., Bishop, L., Frith, S. M. H., DeLuisi, J., Keller, T., Oltmans, S. J., and Fleming, E. L.: Detecting the recovery of total column ozone, J. Geophys. Res.-Atmos., 105, 22201-22210, 2000.

Weber, M., Dhomse, S., Wittrock, F., Richter, A., Sinnhuber, B. M., and Burrows, J.: Dynamical control of $\mathrm{NH}$ and $\mathrm{SH}$ winter/spring total ozone from GOME observations in 1995-2002, Geophys. Res. Lett., 30, 1583, https://doi.org/10.1029/2002GL016799, 2003.

Wilks, D. S.: Statistical methods in the atmospheric sciences, Academic press, 467 pp., 2006.

WMO (World Meteorological Organization): Assessment for Decision-Makers: Scientific Assessment of Ozone Depletion: 2014, 88 pp., Global Ozone Research and Monitoring Project Report No. 56, Geneva, Switzerland, 2014.

Yun, S., Lee, H., Kim, J., Jeong, U., Park, S. S., and Herman, J.: Inter-comparison of $\mathrm{NO}_{2}$ column densities measured by Pandora and OMI over Seoul, Korea, Korean J. Remote Sens., 29, 663670, https://doi.org/10.7780/kjrs.2013.29.6.9, 2013.

Zhao, X., Fioletov, V., Cede, A., Davies, J., and Strong, K.: Accuracy, precision, and temperature dependence of Pandora total ozone measurements estimated from a comparison with the Brewer triad in Toronto, Atmos. Meas. Tech., 9, 5747-5761, https://doi.org/10.5194/amt-9-5747-2016, 2016.

Zerefos, C. S., Tourpali, K., Isaksen, I. S. A., and Schuurmans, C. J. E.: Long term solar induced variations in total ozone, stratospheric temperatures and the tropopause, Adv. Space Res., 27, 1943-1948, 2001 
Ziemke, J. R., Chandra, S., and Bhartia, P. K.: A 25-year data record of atmospheric ozone in the Pacific from Total Ozone Mapping Spectrophotometer (TOMS) cloud slicing: implications for ozone trends in the stratosphere and troposphere, J. Geophys. Res., 110, D15105, https://doi.org/10.1029/2004JD005687, 2005. 